\title{
Uso de fosfatos com diferentes relações flúor:fósforo na alimentação de poedeiras semipesadas na fase de produção
}

\author{
Lúcio Francelino Araújo ${ }^{1}$, Cristiane Soares da Silva Araújo², Otto Mack Junqueira², Luís \\ Carlos Garibaldi Simon Barbosa ${ }^{3}$, Ricardo de Albuquerque ${ }^{4}$, Douglas Emygdio de Faria ${ }^{3}$
}

\footnotetext{
${ }^{1}$ Faculdade de Zootecnia e Engenharia de Alimentos - FZEA/USP, CEP: 13635-900, Pirassununga, SP, Brasil.

2 Faculdade de Ciências Agrárias e Veterinárias - FCAVJ/UNESP, CEP: 148894-900, Jaboticabal, SP, Brasil.

${ }^{3}$ Faculdade de Odontologia de Araçatuba - FOA/UNESP, CEP: 16015-050, Araçatuba, SP, Brasil.

${ }^{4}$ Faculdade de Medicina Veterinária e Zootecnia - FMVZ/USP, CEP: 13635-900, Pirassununga, SP, Brasil.
}

RESUMO - Um experimento foi conduzido para verificar os efeitos de diferentes relações flúor:fósforo (F:P) na dieta sobre o desempenho e as concentrações de cálcio, fósforo, magnésio e flúor na tíbia de poedeiras comerciais semipesadas. Foram utilizadas 160 galinhas poedeiras, distribuídas em delineamento inteiramente casualizado, com quatro tratamentos (fontes de fósforo com diferentes relações flúor:fósforo - 1:40; $1: 60 ; 1: 80 ; 1: 100$ ) e cinco repetições de oito aves. No final do experimento, foram abatidas duas aves de cada repetição para coleta da tíbia e análise dos teores de flúor, cálcio, fósforo e magnésio. As relações flúor:fósforo não afetaram o consumo de ração, a produção de ovos, a conversão alimentar, o peso dos ovos e a gravidade específica. Entretanto, a porcentagem de casca e a espessura da casca foram menores quando a relação F:P foi de 1:100. Apesar da ausência de efeitos na produção de ovos, verificou-se redução de 7,3; 5,4 e 9,8\% na produção entre as aves que receberam ração com a maior relação $\mathrm{F}: \mathrm{P}$ (1:100) em comparação àquelas alimentadas com as rações com as relações de 1:40; 1:60 e 1:80, respectivamente. A deposição óssea de flúor reduziu e a de magnésio aumentou nas aves alimentadas com a ração contendo as maiores relação de F:P. As fontes de fósforo, nas relações fluor:fósforo de 1:40 a 1:80, podem ser utilizadas em dietas para poedeiras comerciais, pois não afetam o desempenho e a qualidade da casca dos ovos.

Palavras-chave: desempenho, fontes de fósforo, minerais ósseos, qualidade de casca

\section{Use of phosphates with different fluorine:phosphorus ratios in diets for brown egg layer hens}

\begin{abstract}
One experiment was conducted to evaluate the effect of different dietary fluorine:phosphorus (F:P) ratios on the performance and bone parameters of layer hens. One hundred and sixty layer hens were randomly allotted to an experimental design with four treatments (phosphorus sources with different F:P ratios - 1:40, 1:60, 1:80, 1:100) with five replicates of eight layers each. At the end of the experiment, two birds per replicate were slaughtered and their tibias were collected to assess the fluorine, calcium, phosphorus and magnesium contents. The different F:P ratios did not affect the feed intake, egg production, feed conversion, egg weight and specific gravity. However, shell percentage and shell thickness were lower when the F:P ratio was 1:100. Despite the absence of effects on egg production, reductions of $7.3,5.4$ and $9.8 \%$ were verified among birds that received diets with higher $\mathrm{F}: \mathrm{P}$ ratios $(1: 100)$ in relation to those fed with diets with 1:40, 1:60 and 1:80 ratios, respectively. The fluorine bone deposition decreased and that of magnesium increased in birds fed diets with the highest F:P ratios. P sources with F:P ratios of 1:40 and 1:80 may be used in diets for commercial layer hens, since they do not affect their performance and egg shell quality.
\end{abstract}

Key Words: bone minerals, performance, phosphorus sources, shell quality

\section{Introdução}

O fosforo (P) é um macromineral envolvido em funções metábolicas essenciais ao organismo e na formação da estrutura óssea dos animais. Em dietas para aves, o fósforo disponível das fontes de origem vegetal não é suficiente para atender às exigencias nutricionais para adequado desempenho e mineralização óssea, por isso, é necessária a suplementação com fontes inorgânicas (Rostagno et al., 2000). Normalmente, o fosfato bicálcico é a principal fonte suplementar de fósforo para as aves, entretanto seu custo é elevado. Em uma ração para frangos de corte ou galinhas de postura, é necessário 1,5 a 1,8\% de fosfato bicálcico para atender às exigências nutricionais 
de fósforo. Com a alta nos preços do milho e de outros grãos, o fosfato bicálcico, utilizado na produção de rações e sais minerais, está mais caro, o que torna a suplementação mineral um dos fatores representativos dos custos das rações para aves.

Assim, os fosfatos de rocha, assim como fertilizantes de uso agrícola, têm despertado interesse como fontes alternativas por serem menos onerosos que os fosfatos convencionais. Contudo, os fertilizantes não são bem utilizáveis pelos animais e possuem elementos químicos, principalmente flúor (F), em quantidades que podem exceder os limites de tolerância para uso na nutrição animal (Thomsen, 1994). A importância do flúor na alimentação não está relacionada aos efeitos de sua deficiência, mas aos riscos de toxicidade por ingestão de alimentos contendo altos teores do mineral. Entretanto, o uso de fosfato de rocha como fonte alternativa de cálcio e fósforo nas dietas visa diminuir o custo de produção das rações. Contudo, não existe padronização dos conteúdos de fósforo, cálcio, flúor e de sua disponibilidade biológica (Guinotte et al., 1991; Junqueira, 1991). Por outro lado, os dados disponíveis na literatura sobre o potencial de utilização desses fosfatos na alimentação de poedeiras comerciais são limitados (Rama Rao et al., 1998; citado por Rama Rao, 2003).

Em criações como a de aves, as inferências indiretas e conexas sobre a nutrição mineral são cada vez mais importantes do ponto de vista científico, especialmente visando ao aumento da eficiência alimentar e à diminuição do custo de produção. Desse modo, considerando a possibilidade de utilização do fosfato de rocha em aves, realizou-se este trabalho com o objetivo de estudar os efeitos do uso de fosfatos de rocha com diferentes relações flúor:fósforo na alimentação sobre o desempenho, as características de qualidade da casca e a concentração de cálcio, fósforo, magnésio e flúor na tíbia de poedeiras semipesadas na fase de produção.

\section{Material e Métodos}

Utilizaram-se 160 galinhas poedeiras (Hy-Line Brown) com aproximadamente 24 semanas, alojadas em pares em gaiolas de arame. O período experimental foi composto de 140 dias. Durante todo o período experimental, as aves receberam água e ração à vontade. O delineamento experimental utilizado foi o inteiramente casualizado, com quatro tratamentos (fonte de fósforo com diferentes relações flúor:fósforo - 1:40; 1:60; 1:80; 1:100) (Tabela 1) e cinco repetições de oito aves. As rações, isocalóricas e isoprotéicas, foram formuladas à base de milho e farelo de soja (Tabela 2), segundo recomendações do NRC (1994).
Foram avaliados a produção (\%) e o peso (g) dos ovos, o consumo de ração (g/ave/dia) e a conversão alimentar (kg de ração/dúzia de ovos). A produção de ovos foi registrada diariamente e o cálculo, realizado no final do período experimental. O peso médio dos ovos foi obtido pela pesagem de todos os ovos produzidos nos últimos dois dias a cada 28 dias do experimento. As características de qualidade de casca de ovos consideradas foram porcentagem de casca (\%), espessura da casca (mm) e gravidade específica dos ovos $\left(\mathrm{g} / \mathrm{mL} \mathrm{H}_{2} \mathrm{O}\right)$. As soluções salinas utilizadas para obtenção da densidade aparente dos ovos foram preparadas conforme recomendações de Moreng \& Avens (1990), com os devidos ajustes para 20 litros de água. A faixa de densidade das soluções foi de 1,065 a 1,095, com intervalos de 0,0025.

Tabela 1 - Composição dos fosfatos avaliados

\begin{tabular}{lcccc}
\hline & \multicolumn{4}{c}{ Relação flúor:fósforo } \\
\cline { 2 - 5 } Índice relativo médio & $1: 40$ & $1: 60$ & $1: 80$ & $1: 100$ \\
\hline Fósforo (\%) & 19,95 & 19,80 & 19,85 & 19,90 \\
Solução citrato (\%) & 98,00 & 96,40 & 93,80 & 90,00 \\
Solução água (\%) & 18,21 & 40,81 & 28,35 & 9,80 \\
Flúor (\%) & 0,50 & 0,33 & 0,25 & 0,19 \\
Fósforo/flúor & 40,00 & 60,00 & 80,00 & 100,00 \\
Cálcio (\%) & 18,00 & 20,44 & 20,17 & 22,80 \\
Acidez (\%) & 5,18 & 1,10 & 0,95 & 0,06 \\
Umidade (\%) & 6,38 & 8,00 & 6,08 & 1,33 \\
\hline
\end{tabular}

Tabela 2 - Composição das dietas experimentais, na matéria natural

\begin{tabular}{|c|c|c|c|c|}
\hline \multirow[t]{2}{*}{ Ingrediente } & \multicolumn{4}{|c|}{ Relação flúor:fósforo } \\
\hline & $1: 40$ & $1: 60$ & $1: 80$ & $1: 100$ \\
\hline Milho & 63,29 & 63,38 & 63,35 & 63,44 \\
\hline Farelo de soja & 23,28 & 23,26 & 23,27 & 23,25 \\
\hline Óleo de soja & 3,00 & 3,00 & 3,00 & 3,00 \\
\hline Calcário & 8,44 & 8,38 & 8,37 & 8,25 \\
\hline Sal & 0,37 & 0,37 & 0,37 & 0,37 \\
\hline Metionina & 0,04 & 0,04 & 0,04 & 0,04 \\
\hline Fosfato bicálcico & 1,08 & 1,08 & 1,10 & 1,16 \\
\hline $\begin{array}{l}\text { Suplemento vitamínico- } \\
\text { mineral }\end{array}$ & 0,50 & 0,50 & 0,50 & 0,50 \\
\hline $\begin{array}{l}\text { Energia metabolizável } \\
(\mathrm{kcal} / \mathrm{kg})\end{array}$ & 2.900 & 2.900 & 2.900 & 2.900 \\
\hline Proteína bruta (\%) & 16,00 & 16,00 & 16,00 & 16,00 \\
\hline Lisina (\%) & 0,80 & 0,80 & 0,80 & 0,80 \\
\hline Metionina (\%) & 0,30 & 0,30 & 0,30 & 0,30 \\
\hline Metionina + Cistina (\%) & 0,58 & 0,58 & 0,58 & 0,58 \\
\hline Fósforo (\%) & 0,32 & 0,32 & 0,32 & 0,32 \\
\hline Cálcio (\%) & 3,50 & 3,50 & 3,50 & 3,50 \\
\hline Sódio (\%) & 0,18 & 0,18 & 0,18 & 0,18 \\
\hline Flúor (mg/kg) & 65 & 36 & 26 & 15 \\
\hline
\end{tabular}

* Suplemento vitamínico-mineral: vit. A - 800.000 UI; vit. D - 100.000 UI; vit. E - $1.000 \mathrm{mg}$; vit. K - $100 \mathrm{mg}$; vit. $\mathrm{B}_{2}-400 \mathrm{mg}$; vit. $\mathrm{B}_{12}-2.000 \mathrm{mcg}$; ácido pantotênico - 440 mg; niacina - 2.000 mg; colina - 50.000 mg; I - 60 mg; Se - 20 mg; $\mathrm{Mn}$ - 6.000 mg; Zn - 10.000 mg; Cu - 15.000 mg; Fe - 10.000 mg; promotor de crescimento - $10.000 \mathrm{mg}$; antioxidante - $125 \mathrm{mg}$; q.s.p. - $1.000 \mathrm{~g}$. 
Ao final do experimento, duas aves por repetição foram abatidas e a tíbia esquerda foi coletada para determinação das deposições de cálcio, fósforo, magnésio e flúor, realizada conforme metodologia descrita por Silva (1990).

A análise dos dados obtidos foi realizada empregando-se o programa ESTAT, 1994 (Sistemas de Análises Estatísticas), desenvolvido pelo Departamento de Ciências Exatas da Faculdade de Ciências Agrárias e Veterinárias/ Universidade Estadual Paulista - Jaboticabal - SP. No caso de efeito significativo das relações flúor:fósforo, as médias foram comparadas pelo teste de Tukey a 5\% de significância.

\section{Resultados e Discussão}

O consumo de ração, a taxa de postura e a conversão alimentar não foram afetados pelas relações flúor:fósforo (Tabela 3), mesmo quando a dieta apresentou maior concentração de flúor (1:40), resultado observado também para o peso dos ovos e a gravidade específica $(\mathrm{P}>0,05)$. Por outro lado, os resultados comprovaram que a dieta com relação fósforo:flúor de 1:100 ocasionou redução na espessura e na porcentagem de casca $(\mathrm{P}<0,05)$ dos ovos.

Rama Rao \& Reddy (2001), avaliando diferentes fontes de fósforo na alimentação de poedeiras comerciais, observaram menor produção de ovos e consumo de ração quando fornecidas fontes de fósforo com maiores concentrações de flúor. Neste mesmo estudo, o peso dos ovos e a qualidade da casca não foram influenciados pelas relações flúor:fósforo estudadas. Em outro trabalho, Rama Rao \& Reddy (2003) avaliaram diversas fontes de fósforo e observaram diminuição no consumo entre as poedeiras alimentadas com rações com elevados níveis de flúor, o que diminuiu a produção de ovos. Os autores ressaltaram que, apesar da diminuição no consumo, a

Tabela 3 - Desempenho das aves e qualidade de casca de ovos de poedeiras comerciais alimentadas com rações com diversas relações flúor:fósforo

\begin{tabular}{lccccc}
\hline & \multicolumn{4}{c}{ Relação flúor:fósforo } & \multicolumn{1}{c}{ CV (\%) } \\
\cline { 2 - 5 } & $1: 40$ & $1: 60$ & $1: 80$ & $1: 100$ & \\
\hline $\begin{array}{l}\text { Consumo de ração } \\
\text { (g/ave-dia) }\end{array}$ & 130 & 127 & 131 & 131 & 4,32 \\
$\begin{array}{l}\text { Taxa de postura (\%) } \\
\text { Conversão alimentar }\end{array}$ & 1,91 & 80,42 & 83,50 & 76,30 & 5,95 \\
$\begin{array}{l}\text { (kg/dúzia) } \\
\text { Peso dos ovos (g) }\end{array}$ & 69 & 6,90 & 1,87 & 1,98 & 3,34 \\
$\begin{array}{l}\text { Casca do ovo (\%) } \\
\text { Gravidade específica }\end{array}$ & 1,093 & $10,04 \mathrm{ab}$ & $9,93 \mathrm{ab}$ & $9,89 \mathrm{~b}$ & 2,16 \\
$\begin{array}{l}\text { Expessura de } \\
\text { casca (mm) }\end{array}$ & $0,435 \mathrm{a}$ & $0,445 \mathrm{a}$ & $0,444 \mathrm{a}$ & $0,425 \mathrm{~b}$ & 1,97 \\
\hline
\end{tabular}

Médias seguidas de mesma letra minúscula (linha) dentro de cada variável analisada não diferem $(\mathrm{P} \leq 0,05)$ pelo teste Tukey. qualidade da casca não foi afetada, confirmando resultados obtidos por Said et al. (1979) e Van Toledo \& Combs (1984). Os resultados encontrados neste estudo diferem parcialmente dos relatados por esses autores, provavelmente em decorrência da menor concentração de flúor nos fosfatos avaliados por esses autores.

Quando se utilizam fosfatos de rocha na alimentação de aves, com altas concentrações de flúor, diversos mecanismos podem influenciar negativamente a produção de ovos. Níveis elevados de flúor na dieta reduzem a utilização de energia (Gardiner et al., 1968), possivelmente por inibirem a oxidação de ácidos graxos (Johnson \& Lardy, 1950) e a lipase intestinal (Suttie \& Phillips, 1960). De acordo com Senkoylu (1983) e Hahn \& guenter (1986), o flúor da dieta influencia sobretudo o consumo de ração, pois afeta o centro do apetite no cérebro, prejudicando o ganho de peso e a produção de ovos e, em menor intensidade, a mineralização óssea. Desse modo, a taxa de produção é muito mais sensível ao teor de flúor na dieta que o critério de mineralização óssea.

Embora a relação flúor:fósforo da dieta não tenha influenciado significativamente a produção de ovos, houve redução de 7,3; 5,4 e 9,8\% na produção das aves alimentadas com a ração com a maior relação flúor:fósforo (1:100) em comparação às aves alimentadas com as rações com as relações 1:40; 1:60 e 1:80, respectivamente.

A deposição de cálcio e fósforo não foi afetada pelas relações flúor:fósforo das dietas (Tabela 4), entretanto, conforme aumentou a amplitude da relação flúor:fósforo, a deposição de magnésio nos ossos também melhorou, contrariando observações de Chan et al. (1973) e Merkley (1976), que verificaram maior deposição óssea de magnésio quando aumentaram o teor de flúor da fonte utilizada. Por outro lado, a concentração de flúor na tíbia foi proporcional à concentração desse mineral na dieta.

Esses resultados foram semelhantes aos encontrados por Araújo (2004), que não observou efeito dos níveis de flúor da dieta sobre a deposição óssea de cálcio e fósforo

Tabela 4 - Concentração de minerais na tíbia de poedeiras comerciais $(\mathrm{g} / \mathrm{kg})$ alimentadas com rações com diferentes relações flúor:fósforo

\begin{tabular}{lccccc}
\hline Mineral & & \multicolumn{2}{c}{ Relação } & flúor:fósforo & \multicolumn{2}{c}{ CV (\%) } \\
\cline { 3 - 5 } & $1: 40$ & $1: 60$ & $1: 80$ & $1: 100$ & \\
\hline Cálcio & 374,21 & 395,47 & 417,43 & 426,15 & 4,75 \\
Fósforo & 178,81 & 187,07 & 196,31 & 201,96 & 2,11 \\
Magnésio & $6,23 \mathrm{~b}$ & $7,73 \mathrm{ab}$ & $8,71 \mathrm{a}$ & $8,82 \mathrm{a}$ & 5,11 \\
Flúor & $1,73 \mathrm{a}$ & 0,97b & 0,25b & $0,19 \mathrm{c}$ & 4,83 \\
\hline
\end{tabular}

Médias seguidas de mesma letra minúscula (linha) dentro de cada variável analisada não diferem significativamente a 5\% pelo teste Tukey. 
em frangos de corte. Esse autor observou também diminuição na concentração de magnésio quando reduziu a relação flúor:fósforo da dieta.

A quantidade de flúor depositado nos ossos parece estar diretamente relacionada à concentração na dieta. Neste trabalho, a deposição desse mineral na tíbia foi consideravelmente maior nas aves alimentadas com a ração com relação 1:40. Semelhantemente, vários trabalhos (Miller \& Joukovsky, 1953; Pool et al., 1965; Michel et al., 1984; Suttie et al., 1984) comprovam relação entre a quantidade de flúor na dieta e sua deposição nos ossos. Apesar dos relatos de Chang et al. (1977) de que o aumento de flúor na dieta reduz a absorção de fósforo e aumenta a excreção de cálcio, alterando sua deposição óssea, nesta pesquisa, os níveis desses minerais não foram influenciados pelas relações flúor:fósforo das dietas.

\section{Conclusões}

Relações fluor:fósforo 1:40 a 1:80 em dietas para poedeiras comerciais não afetam o desempenho das aves nem a qualidade da casca dos ovos.

\section{Literatura Citada}

ARAUJO, L.F. Fontes e níveis de fósforo para frangos de corte e poedeiras comerciais. 2004. 220f. Tese (Livre Docência). Universidade de São Paulo, Pirassununga, 2004.

CHAN, M.M.; RUCKER, R.B.; ZEMAN, F. et al. Effect of fluorine on bone formation strength in Japanese quail. Journal of Nutrition, v.103, n.10, p.1431-1440, 1973.

CHANG, Y.O.; PAN, M.; THOMAS, V. The effect of fluoride on calcium absortion in rats. Nutrition Reports International, v.16, p.539-547.

ESTAT. Sistema de análises estatísticas. Jaboticabal: Departamento de Ciências Exatas, Universidade Estadual Paulista, 1994. (CD-ROM).

GARDNER, E.E.; PARKER, H.E.; CARRICK, C.W. Soft phosphate in chick rations. Poultry Science, v.38, p.721-727, 1959.

GUINOTTE, F.; NYS, Y.; MONREDON, F. The effects of particle size and origin of calcium carbonate on performance and ossification characteristics in broiler chicks. Poultry Science, v.70, n.9, p.1908-1920, 1991.

HAHN, P.H.B.; GUENTER, W. Effect of dietary fluoride and aluminum on laying hen performance and fluoride concentration in blood, soft tissues, bone and egg. Poultry Science, v.65, p.1343-1349, 1986.
JOHNSON, R.B.; LARDY, H.A. Orthophosphate uptake during the oxidation of fatty acids. Journal of Biological Chemistry, v.184, p.235-240, 1950.

JUNQUEIRA, O.M. Desempenho produtivo de aves alimentadas com fosfato não convencionais. In: MINI SIMPÓSIO DO COLÉGIO BRASILEIRO DE NUTRIÇÃO, 6., 1991, Campinas. Anais... Campinas: EMBRAPA, 1991. p.121-136.

MERKLEY, J.W. Increase bone strength in coop-reared broilers provided fluoridated water. Poultry Science, v.55, p.13131319, 1976.

MICHEL, J.N.; SUTTIE, J.W.; SUNDE, M.L. Fluorine deposition in bone as related to physiological state. Poultry Science, v.63, p.1407-1411, 1984.

MILLER, M.W.; JOUKOVSKY, V.V. Availability of phosphorus from various phosphate materials for chicks. Poultry Science, v.32, p.78-81, 1953.

MORENG, R.E.; AVENS, J.S. Ciência e produção de aves. São Paulo: Roca, 1990. 380p.

NATIONAL RESEARCH COUNCIL - NRC. Nutrient requirements of poultry. 9.rev.ed. Washington, D.C.: National Academy Press, 1994. 157p.

NEVES, T. [2008]. A alta de preços das matérias-primas. Produção Animal-Avicultura, 13 ed., Avisite, Mundo Agro, Campinas. Disponível em: <http://www.avicultura.com.pt/ index.php? option=com_content\&task=view\&id=501> Acesso em: 29/7/2008.

POOL, M.F.; TANGO, W.J.; KLOSE, A.A. The fluoride content of commercial of broiler backs and necks. Poultry Science, v.44, p.1545-1550, 1965.

RAMA RAO, S.V.; REDDY, V.R. Relative bio-availability and utilization of phosphatic fertilizers as sources of phosphorus in broilers and layers. British Poultry Science, v.44, p.96-103, 2003.

RAMA RAO, S.V.; REDDY, V.R. Utilization of different phosphorus sources in relation to their fluorine content for broilers and layers. British Poultry Science, v.42, p.376-383, 2001.

ROSTAGNO, H.S.; ALBINO, L.F.T.; DONZELE, J.L. et al. Composição de alimentos e exigências nutricionais de aves e suinos. Tabelas brasileiras para aves e suinos. Viçosa, MG: Editora UFV, 2000. 141p.

SAID, N.W.; SUNDE, M.L.; BIRD, H.R. et al. Raw rock phosphate as a phosphorus supplement for growing pullets and layers. Poultry Science, v.58, p.1557-1563, 1979.

SENKOYLU, N. The possibilities of using mazidagiraw rock phosphate as a source of inorganic phosphorus in broiler and laying hen rations. Poultry Abstracts, v.11, p.31, 1985.

SILVA, D.J.; QUEIROZ, A.C. Análise de alimentos (métodos químicos e biológicos). 2.ed. Viçosa, MG: UFV, 2002. 25p.

SUTTIE, J.W.; PHILLIPS, P.H. Fat utilization in fluoride fed rat. Journal of Nutrition, v.72, p.429-434, 1960.

SUTTIE, J.W.; KOLSTAD, D.L.; SUNDE, M.L. Fluorine tolerance of young chick and turkey poult. Poultry Science, v.63, p.738-743, 1984.

THOMSEN, J. From rock to feed production of phosphates. Feed Mix, Special Issue on Phosphates, p.16-17, 1994.

Van TOLEDO, B.; COMBS, G.F. Fluorosis in the laying hen. Poultry Science, v.63, p.1543-1548, 1984. 